\title{
FETAL RESORPTION INDUCED BY DISULFIRAM IN RATS
}

\author{
M. P. SALGO AND G. OSTER* \\ Department of Physiology and *Graduate School of Biological Sciences, \\ The Mount Sinai School of Medicine, City University of New York, \\ N.Y. 10029, U.S.A.
}

(Received 17th September 1973)

\begin{abstract}
Summary. When pregnant rats given disulfiram, a copper-chelating agent, orally at a dose of $100 \mathrm{mg}$ per day from Day 3 of pregnancy were killed on Day 12 or $13,83 \%$ of the conceptuses showed fetal resorption. In any rat, fetal resorption was uniform among all the conceptuses. The similarity of our results with those found by others for rats fed on a copper-deficient diet suggests that disulfiram renders copper unavailable for the developing embryo.
\end{abstract}

It has long been known that livestock raised on fodder from copper-deficient soil exhibit reproductive failure (for review, see Underwood, 1971). Rats fed on a copper-deficient diet conceive but the pregnancy is not maintained (Dutt \& Mills, 1960). Hall \& Howell (1969) and Howell \& Hall (1969) found that rats fed on a copper-deficient diet started 6 weeks before mating did not produce litters. Implantation occurred but the fetuses had been resorbed by Day 13 . When copper was supplied the litters developed normally. In our search for a practical oral abortifacient, it occurred to us that feeding a copper chelating agent, such as disulfiram, might likewise be effective.

Primiparous Sprague-Dawley rats weighing 200 to $250 \mathrm{~g}$ and of standard gestation length, as judged by the presence of a copulatory plug (Day 1 of pregnancy), were obtained from Marland Farms. The rats were allowed free access to powdered Purina Laboratory Chow except in one paired feeding experiment in which the amount of food that each disulfiram-treated rat consumed in a day was noted and this amount of food was given to the paired untreated control rat the following day.

Initial trials consisted of giving copper-chelating agents in the feed from Day 3 on. Disodium ethylenediamine tetra-acetic acid $\left(\mathrm{Na}_{2}\right.$ EDTA: Fisher Scientific), penicillamine (Cuprimine: Merck Sharp and Dohme), and disulfiram (Antabuse: Ayerst) were mixed with the feed at weight concentrations of $3 \%, 1 \%$ and $1 \%$, respectively. Only disulfiram induced fetal resorption. Because disulfiram caused anorexia it was given by oral intubation in all subsequent experiments. Water suspensions of disulfiram at $100 \mathrm{mg} / \mathrm{ml}$ were made by homogenizing Antabuse pellets in a laboratory blender. To eliminate the factor of reduction in food intake caused by disulfiram, the paired feeding experiment was also conducted. 
Rats were killed by decapitation on Day 12 or 13 or occasionally, to note possible teratological effects, on Day 21. Resorption of the implantation was characterized not only by a small fetus (one-fifth the size of the controls) but also by haemorrhage and disintegration. The placenta was also resorbed.

For rats treated with $100 \mathrm{mg}$ disulfiram/day, $83 \%$ of the 124 implantation sites from the eleven rats showed resorption. The remaining embryos were alive but smaller (by about $20 \%$ ) than those of the controls (Table 1). (Control rats, even in paired feeding experiments, showed no fetal resorption.) Toxic reactions occurred, ranging from lethargy seen in most animals after 5 days of treatment with disulfiram to coma and death in about one third of the rats after 8 days of treatment. Symptoms of the sicker animals included foulsmelling discharge appearing in the fur surrounding the genital area, dried blood at the nostrils and shrunken appearance of the eyes. Autopsies of such rats revealed discoloration of the liver and pulmonary haemorrhage.

Table 1. Fetal resorption with disulfiram

\begin{tabular}{l|c|c|c|c|c}
\hline \multicolumn{1}{c|}{ Treatment } & No. of rats & Day of autopsy & $\begin{array}{c}\text { No. of resorptions/ } \\
\text { no. of implantations }\end{array}$ & \% resorption & $\begin{array}{c}\text { Av. wt of } \\
\text { fetuses and } \\
\text { uterus }(\mathrm{g})\end{array}$ \\
\hline Disulfiram & 8 & 12 & $77 / 87$ & 88 & $0 \cdot 5^{*}$ \\
Control & 4 & 12 & $0 / 52$ & 0 & $2 \cdot 7$ \\
Disulfiram & 3 & 13 & $26 / 37$ & 70 & $2 \cdot 8^{*}$ \\
Control (pair-fed) & 2 & 13 & $0 / 25$ & 0 & $6 \cdot 8$ \\
\hline
\end{tabular}

Disulfiram was given orally in a dose of $100 \mathrm{mg} /$ day, starting on Day 3 of pregnancy.

* Compared to controls $(P \leqslant 0 \cdot 001)$.

Lowering the dosage to $50 \mathrm{mg} /$ day greatly reduced the toxic effects but no fetal resorption occurred in four rats examined. Continuing this dosage to Day 21 had no effect on the viability of the fetuses, nor did they exhibit any teratological effects as judged by gross examination. Similarly, six rats given $100 \mathrm{mg} /$ day on regimens started later than Day 8 showed neither fetal resorption nor gross malformations.

Disulfiram itself is not, strictly speaking, a chelating agent. It is reduced in vivo to form the mercaptan, diethyldithiocarbamate (Strömme, 1965). The carbamate is a well-known chelating agent specific for copper, with much less chelation for ferric ion. In rats, the copper-containing enzyme, dopamine $\beta$-hydroxylase, is inhibited in vivo with a dosage of disulfiram of about $100 \mathrm{mg}$ / day (Goldstein \& Najakima, 1967).

The fact that a copper-deficient diet and disulfiram administration both result in fetal resorption around Day 13 indicates a similarity in mechanism. The variability between litters after disulfiram administration may be a consequence of differences in food intake and hence of copper ingestion. With less severe copper deficiencies, Hall \& Howell (1969) found more variation in the timing and degree of fetal resorption. Copper could play a critical rôle in development in a variety of ways: deficiencies leading to elastin disorders resulting in internal haemorrhage in the rat fetus (O'Dell, Hardwick \& 
Reynolds, 1961) and disorders of erythropoiesis and bone development (Scheinberg \& Sternlieb, 1960).

Disulfiram differs from other agents which cause fetal resorption, such as aminopterin (Thiersch \& Phillips, 1950), in that at lower doses it causes no apparent gross malformations in rats (see also Faure-Tissot \& Delatour, 1965; Robens, 1969). On the other hand, the high doses of disulfiram required for fetal resorption in rats are toxic to the mother.

This work was supported by the Ford Foundation on Grant No. 690-0106.

\section{REFERENCES}

Dutr, B. \& Milus, C. F. (1960) Reproductive failure in rats due to copper deficiency. J. comp. Path. Ther. 70, 120.

FAure-Tissot, M. \& Delatour, P. (1965) Psychopharmalogie et teratogenèse à propos du disulfirame: essai expérimental. Annls med.-psychol. 1, 735.

Goldstein, M. \& Najakima, K. (1967) The effect of disulfiram on catecholamine levels in the brain. 7. Pharmac. exp. Ther. 157, 96.

Hall, G. A. \& Howell, J. McG. (1969) The effect of copper deficiency on reproduction in the female rat. Br. F. Nutr. 23, 41 .

Howell, J. MaC. \& Hall, G. A. (1969) Histological observations on foetal resorption in copperdeficient rats. Br. F. Nutr. 23, 47.

O'Dell, B. K., HaRdwick, B. G. \& Reynolds, G. (1961) Mineral deficiencies of milk and congenital malformations in the rat. 7 . Nutr. 73, 151.

RoBens, J. F. (1969) Teratologic studies of carbaryl, diazionin, norea, disulfiram and thiram in small laboratory animals. Toxicol. appl. Pharmac. 15, 152.

Scheinderg, I. H. \& Sternlieb, I. (1960) Copper metabolism. Pharmac. Rev. 12, 355.

Ströмme, J. H. (1965) Metabolism of disulfiram and diethyldithiocarbamate in rats with demonstration of an in vivo ethanol-induced inhibition of the glucuronic acid conjugation of the thiol. Biochem. Pharmac. 14, 393.

Thiersch, J. B. \& Phillips, F. S. (1950) Effect of 4-amino-pterolglutamic acid (aminopterin) on early pregnancy. Proc. Soc. exp. Biol. Med. 74, 264.

Underwood, E. J. (1971) Trace Elements in Human and Animal Nutrition, 3rd edn. Academic Press, New York. 